\title{
Developmental differences in carcass, meat quality and muscle fibre characteristics between the Landrace and a Chinese native pig
}

\author{
Fawen Dai, Dingyuan Feng, Qingyun Cao, Hui Ye, Changmin Zhang, Weiguang Xia \\ and Jianjun Zuo \\ College of Animal Science, South China Agricultural University, Guangzhou, Guangdong Province, \\ 510642, P. R. China
}

\begin{abstract}
This experiment was conducted to compare carcass and meat quality traits, and muscle fibre characteristics in the longissimus muscle of the Landrace [an European pig breed] and the Lantang [a Chinese native pig breed] at the ages of 60,90 and 150 days. The characteristics of muscle fibres were determined by real-time reverse transcription polymerase chain reaction (RT-PCR) and histological methods (ATPase and succinodehydrogenase, SDH). A significant age difference was observed in loin eye area (LEA), backfat thickness (BF), $\mathrm{pH}_{45 \text { min }}, \mathrm{pH}_{24}$ h, drip loss, moisture, ash, number percentages of $\alpha \mathrm{R}$ and $\alpha \mathrm{W}$ fibres, muscle fibre cross-sectional area and mRNA expression of myosin heavy chain (MyHC)-slow and MyHC-IIb. The Lantang showed a higher intramuscular fat (IMF) content and BF than the Landrace, while the Landrace exhibited a higher LEA and ash content than the Lantang. Both breeds exhibited similar developments in muscle fibre composition, and there were small differences in muscle fibre composition and muscle fibre cross-sectional area. However, Landrace pigs showed a significantly higher mRNA relative expression of MyHC-IIb. These results suggested that age was an important factor in the variation of carcass, meat quality traits and characteristics of muscle fibres. The main differences between the breeds at the same age were LEA, BF, IMF and ash contents, and fast glycolytic MyHC-IIb in the mRNA level.
\end{abstract}

Keywords: Breeds, Lantang, age, muscle fibres, carcass, meat quality

${ }^{\#}$ Corresponding author. E-mail: fengdy@scau.edu.cn, daifawen@126.com

\section{Introduction}

Skeletal muscle comprised of muscle fibres, intramuscular fat, blood vessels and other tissues. Traditionally, muscle fibres are classified as an oxidative type (I), a glycolytic type (IIb) or an intermediate type (IIa) according to their ATPase stability to acid or alkali solutions (Brooke \& Kaiser, 1970). Muscle fibres could also be classified as slow-twitch red $(\beta R)$, fast-twitch red $(\alpha \mathrm{R})$ or fast-twitch white $(\alpha \mathrm{W})$ (Ashmore \& Doerr, 1971) or also slow-twitch oxidative (SO), fast-twitch oxidative glycolytic (FOG) or fast-twitch glycolytic (FG) (Peter et al., 1972) based on the activities of ATPase and oxidative enzymes. Four major sarcomeric myosin heavy chains (MyHC), i.e. slow-twitch oxidative (slow/I), fast-twitch oxidative glycolytic (IIa), fast-twitch glycolytic (IIb) and intermediate fast-twitch oxidative glycolytic (IIx) are expressed in pig skeletal muscle during postnatal development (Lefaucheur et al., 2002). The types MyHC-slow and MyHC-IIb represent two extreme metabolic muscle fibres, which exert some level of significance in the study of meat quality (Ryu \& Kim, 2005; Park et al., 2007).

Previous studies have indicated that muscle fibre composition and muscle cross-sectional area had a profound influence on meat quality traits. Muscle fibre size and capillary density in pigs seem to be important factors that influence the metabolic response at slaughter and thus meat quality (Essen-Gustavsson et al., 1992). Intramuscular lipids in the longissimus muscle of pigs are stored mainly in type I fibres and some type IIA fibres (Essen-Gustavsson et al., 1994). The percentage of type IIb fibre in the longissimus muscle from crossbred pigs is negatively related to $\mathrm{pH}_{45 \text { min }}$ and positively to R-value and drip loss (Ryu \& Kim, 2005). Thus, the increase of type IIb fibre accelerates the post mortem metabolic rate, and therefore the deterioration of meat quality. However, there are some differences in the relationship between fibre type composition and meat quality traits of halothane-negative and halothane-carrier pigs (Eggert et al., 2002). Therefore, the influence of genetic factors on characteristics of muscle fibre types should be taken into consideration when meat quality is studied.

The Langtang pig is native to the southern part of China. The breed has a lower growth performance than other Chinese native breeds, and generally possessing more intramuscular fat and better meat quality than most commercial European pigs such as the Landrace. However, there is only limited scientific information 
available on the meat quality of Lantang pigs. Thus, the current study was conducted to compare carcass, meat quality traits and muscle fibre characteristics at mRNA and histological levels between pure Lantang and Landrace pigs at different ages, to better understand meat quality characteristics of Lantang pigs.

\section{Materials and Methods}

Fifty Lantang pigs (20 barrows and 30 intact gilts) of similar liveweight $(11.63 \pm 0.16 \mathrm{~kg}$ ) as well as 70 Landrace pigs (22 barrows and 48 intact gilts) of similar liveweights $(15.19 \pm 0.35 \mathrm{~kg}$ ) at 60 days of age were selected and used in this study. They were divided into five replicates based on their weights and sexes, respectively. Each replicate of the Lantang group had 10 pigs and each of the Landrace, 14 pigs. Maize-soyabean meal-based diets in mash form (Table 1) and water were provided ad libitum during the experimental period.

One barrow per replicate with a liveweight close to the mean was slaughtered at 60,90 and 150 days of age. Within 45 min post mortem, muscle samples for histological analysis were obtained from the longissimus muscle at the last rib from the left side of the carcass. The samples were cut into $0.5 \times 0.5 \times 1.0 \mathrm{~cm}$ sizes and quickly preserved in liquid nitrogen until required for analysis. Samples for mRNA expression analysis were also collected from the longissimus muscle at the last rib from the left side of the carcass and preserved in liquid nitrogen. The left half of a carcass was taken to evaluate carcass traits and the longissimus muscle from the left half was taken to determine meat quality.

Muscle $\mathrm{pH}$ was measured at $45 \mathrm{~min}$ and $24 \mathrm{~h}$ post mortem in the longissimus muscle (between the $13^{\text {th }}$ and $14^{\text {th }}$ rib) using a DELTA-320 portable $\mathrm{pH}$-meter. Muscle colour measurements (Opto-star value) were taken at $2 \mathrm{~h}$ post mortem on the exposed cut surface of the longissimus muscle (at the last-rib level). Drip loss was determined by suspending the muscle samples that were standardized for surface area and weight in an inflated plastic bag for $24 \mathrm{~h}$ and $48 \mathrm{~h}$ at $4{ }^{\circ} \mathrm{C}$ (Honikel et al., 1986).

Intramuscular fat (IMF) percentage was determined in the longissimus muscle by ether extraction in a Soxhlet apparatus after acid hydrolysis (ISO 1443-1978). Moisture percentage was obtained by drying $\left(125^{\circ} \mathrm{C}\right.$ ) to a constant weight (AOAC 950.46) and ash percentage was determined by incineration $\left(550 \pm 25^{\circ} \mathrm{C}\right)$ until the ash reached a white colour (ISO 936-1978).

Carcasses were chilled for $6 \mathrm{~h}$, where-after the midline backfat thickness was measured with a ruler at the first and last ribs, and the last lumbar vertebra. The mean of those three measurements was used as backfat thickness (BF). The loin eye area (LEA) was traced onto acetate paper at the last rib level and calculated on the basis of loin eye height and loin eye width with 0.7 as the coefficient (Zhang et al., 2007).

Table 1 The ingredient and composition of the basal diets during different stages of the study

\begin{tabular}{|c|c|c|c|c|c|c|}
\hline \multirow{2}{*}{ Ingredient } & \multicolumn{2}{|c|}{ 61-90 days } & \multicolumn{2}{|c|}{ 91-120 days } & \multicolumn{2}{|c|}{ 121-150 days } \\
\hline & LT & LR & LT & LR & LT & LR \\
\hline Maize & 65 & 66 & 63 & 65 & 64 & 68 \\
\hline Soyabean meal & 23 & 26 & 15 & 24 & 10 & 20 \\
\hline Fish meal & & 2 & & & & \\
\hline Bran & 8 & & 18 & 6 & 22 & 8 \\
\hline Oil & & 2 & & & & \\
\hline Premix $^{1}$ & 4 & 4 & 4 & 4 & 4 & 4 \\
\hline Nutrient composition & & & & & & \\
\hline Digestible energy $(\mathrm{MJ} / \mathrm{kg})$ & 13.18 & 13.60 & 12.56 & 13.18 & 12.13 & 13.00 \\
\hline Crude protein $(\mathrm{g} / \mathrm{kg})$ & 165 & 180 & 140 & 165 & 125 & 150 \\
\hline Lysine (g/kg) & 9.0 & 10.5 & 7.5 & 9.5 & 6.5 & 8.5 \\
\hline Meth+cyst (g/kg) & 5.8 & 6.1 & 5.3 & 6.0 & 5.0 & 5.7 \\
\hline Threonine (g/kg) & 6.1 & 6.9 & 5.1 & 6.2 & 4.4 & 5.7 \\
\hline Calcium $(\mathrm{g} / \mathrm{kg})$ & 7.0 & 7.0 & 6.5 & 6.5 & 6.2 & 6.2 \\
\hline Available phosphorus (\%) & 3.2 & 3.3 & 3.0 & 3.0 & 2.8 & 2.8 \\
\hline
\end{tabular}

${ }^{1}$ Supplied per kg of diet: $20000 \mathrm{IU}$ vitamin A; $2000 \mathrm{IU}$ vitamin D; $60 \mathrm{IU}$ vitamin E; $2 \mathrm{mg}$ vitamin $\mathrm{K} ; 2 \mathrm{mg}$ vitamin B ${ }_{1}$; $10 \mathrm{mg}$ riboflavin; $20 \mathrm{mg}$ pantothenic acid; $40 \mathrm{mg}$ niacin, $5 \mathrm{mg}$ vitamin $\mathrm{B}_{6} ; 40 \mu \mathrm{g}$ vitamin $\mathrm{B}_{12} ; 1.5 \mathrm{mg}$ folic acid; $200 \mathrm{mg}$ vitamin C; $600 \mathrm{mg}$ choline chloride; $75 \mathrm{mg}$ manganese; $120 \mathrm{mg}$ zinc; $140 \mathrm{mg}$ iron; $8 \mathrm{mg}$ copper; $0.4 \mathrm{mg}$ iodine; $0.3 \mathrm{mg}$ selenium.

Meth+cys - Methionine+cysteine. 
Serial transverse muscle sections $(12 \mu \mathrm{m})$ were obtained from each frozen muscle sample using a cryostat microtome (Leica, Germany) at $-25^{\circ} \mathrm{C}$ and mounted on glass slides. Myosin ATPase and SDH activities were detected after acid (pH 4.3) pre-incubation (Solomon \& Dunn, 1988). To avoid casting, the unfixed sections were kept at room temperature for $30 \mathrm{~min}$ before pre-incubation. The muscle fibres were divided into types $\beta \mathrm{R}, \alpha \mathrm{R}$ and $\alpha \mathrm{W}$ according to the nomenclature of Ashmore \& Doerr (1971).

All samples were examined by an image processing system (Motic China Group Co. Ltd). The operational system consisted of an optical microscope and a standard workstation computer that controlled the image analysis. Approximately 500 to 600 fibres were evaluated per sample. The fibre number percentage was obtained from the ratio of the number of each fibre type to the total number of fibres counted, and fibre area was the average area of at least 50 fibres of each fibre type.

Total RNA was isolated from skeletal muscle tissue using TRIZOL reagent (Invitrogen) and purified with DNase I (Invitrogen) according to the manufacturer's instructions. In brief, skeletal muscle tissues were homogenised in TRIZOL reagent (50 to $100 \mathrm{mg}$ of tissue/1 $\mathrm{mL}$ TRIZOL). The homogenised samples were incubated at room temperature for $5 \mathrm{~min}$. After incubation, $0.2 \mathrm{~mL}$ chloroform was added per $1 \mathrm{~mL}$ of TRIZOL and the tubes were shaken vigorously for $10 \mathrm{sec}$ and incubated at room temperature for $5 \mathrm{~min}$. The samples were subsequently centrifuged at $12000 \mathrm{~g}$ for $15 \mathrm{~min}$ at $4{ }^{\circ} \mathrm{C}$. The upper aqueous phase (containing the RNA) was transferred to a fresh RNase-free tube and the RNA was precipitated by mixing with an equal volume of isopropyl alcohol. The samples were incubated at $-20^{\circ} \mathrm{C}$ for $1 \mathrm{~h}$ and centrifuged at $12000 \mathrm{~g}$ for $10 \mathrm{~min}$ at $4{ }^{\circ} \mathrm{C}$. The supernatant was removed and the pellet was washed with $1 \mathrm{~mL}$ of $75 \%$ ethanol. Samples were centrifuged at $12000 \mathrm{~g}$ for $2 \mathrm{~min}$ at $4{ }^{\circ} \mathrm{C}$. The RNA pellets were briefly dried and dissolved in $40 \mu \mathrm{L}$ RNase-free water. Then the RNA solutions were immediately precipitated by adding $100 \mu \mathrm{L}$ of $100 \%$ ethanol and $5 \mu \mathrm{L} 3 \mathrm{M}$ Na-Acetate ( $\mathrm{pH}$ 5.2). These solutions were stored at $-20^{\circ} \mathrm{C}$ for at least $1 \mathrm{~h}$ before centrifugation at $12000 \mathrm{~g}$ for 20 min at $4{ }^{\circ} \mathrm{C}$. The RNA pellets were washed twice in $75 \%$ ethanol, dried at room temperature and dissolved in $40 \mu \mathrm{L}$ RNase-free water. Then the contaminating DNA in a sample of $8 \mu \mathrm{g}$ RNA was removed by adding 0.4 $\mu \mathrm{L}$ of $5 \mathrm{U} / \mu \mathrm{L}$ DNase I (Invitrogen) and incubated at $37^{\circ} \mathrm{C}$ for $20 \mathrm{~min}$. The reaction was stopped by incubating at $55^{\circ} \mathrm{C}$ for $5 \mathrm{~min}$. The RNA quality was checked using $1.0 \%$ agarose gel electrophoresis and stained with 0.5 $\mu \mathrm{g} / \mathrm{mL}$ ethidium bromide. The RNA had an OD260 $\mathrm{nm}$ : OD280 $\mathrm{nm}$ ratio between 1.8 and 2.0. Synthesis of the first strand of cDNA was performed with oligo(dt)20 and Superscript II reverse transcriptase (Invitrogen).

Real-time PCR was performed using one-step SYBR Green PCR Mix (Takara, Dalian, China), containing $\mathrm{MgCl}_{2}$, dNTP, and Hotstar Taq polymerase. Primers were designed specifically for each gene by using Primers 5.0 software. Amplification and melting curve analysis were performed in ABI 7500 (Applied BioSystems). Melting curve analysis was conducted to confirm the specificity of each product and the sizes of the products verified on ethidium bromide-stained 1.0\% agarose gels in a Tris acetate-EDTA buffer. The relative mRNA expression was calculated by $2^{-\Delta \mathrm{Ct}}(\Delta \mathrm{Ct}=\Delta \mathrm{Ct}$ of the target gene $-\Delta \mathrm{Ct}$ of the housekeeping gene) (Livak Kenneth \& Schmittgen Thomas, 2001). Real-time PCR efficiency was acquired by the amplification of serial dilution of the plasmid containing target fragment according to the equation $10^{(-1 / \text { slope })}$ and was consistent between target gene and 18S. Negative controls were performed in which water was substituting the tissue cDNA sample. The relative expression of target genes was normalized according to $18 \mathrm{~S}$ (housekeeping gene). Details of primer design and runs of real-time RT-PCR were presented in Table 2.

All the results were processed with SAS V8 (The SAS Institute, Cary, N.C., USA). A general linear model was used to evaluate the difference $(\mathrm{P}<0.05)$ between ages $(60,90$ and 150 days) and between breeds (LT and LR pigs). The model included the effects of age, breed and age $\times$ breed interaction. The results are presented as means \pm standard error of the mean (s.e.m.).

Table 2 Primers and runs of the real-time RT-PCR assays

\begin{tabular}{|c|c|c|c|}
\hline Gene & Primer sequence & product (bp) & Slope \\
\hline MyHC-slow & $\begin{array}{l}\text { Forward: 5'-GAGAAGGGCAAAGGCAAGG-3' } \\
\text { Reverse: 5'-ACGAAGTGGGGATGTGTGG-3' }\end{array}$ & 116 & -3.19 \\
\hline MyHC-IIb & $\begin{array}{l}\text { Forward: 5'-GTCACCGTCAACCCCTACAAGT-3' } \\
\text { Reverse: 5'-CGGCGATTGTGGCAAAGTA-3' }\end{array}$ & 232 & -3.37 \\
\hline $18 \mathrm{~S}$ & $\begin{array}{l}\text { Forward: 5'-AATTCCGATAACGAACGAGACT-3' } \\
\text { Reverse: 5'-GGACATCTAAGGGCATCACAG-3' }\end{array}$ & 140 & -3.39 \\
\hline
\end{tabular}




\section{Results and Discussion}

Many intrinsic and extrinsic factors are known to determine meat quality traits. The present experiment illustrated that age was a key factor in affecting pig carcass and meat quality traits. Age differences in LEA, BF, $\mathrm{pH}_{24 \mathrm{~h}}$, moisture and ash percentages were significant $(\mathrm{P}<0.01)$ (Table 3). The $\mathrm{pH}_{45 \min }$ and drip loss in the longissimus muscle also differed $(\mathrm{P}<0.05)$ at different ages.

Table 3 Carcass and meat quality traits in the Lantang (LT) and Landrace (LR) pigs

\begin{tabular}{|c|c|c|c|c|c|c|c|c|c|c|}
\hline & \multicolumn{2}{|c|}{60 days } & \multicolumn{2}{|c|}{90 days } & \multicolumn{2}{|c|}{150 days } & \multirow[b]{2}{*}{ s.e.m. } & \multicolumn{3}{|c|}{ Significant level } \\
\hline & LT & LR & LT & LR & LT & LR & & Age & Breed & AgexBreed \\
\hline LEA $\mathrm{cm}^{2}$ & 9.12 & 13.33 & 12.43 & 21.86 & 27.16 & 49.63 & 2.66 & $* *$ & $* *$ & $* *$ \\
\hline $\mathrm{BF} \mathrm{mm}$ & 6.61 & 4.21 & 13.94 & 8.04 & 22.24 & 21.73 & 1.44 & $* *$ & * & NS \\
\hline $\mathrm{pH}_{45 \min }$ & 6.32 & 6.56 & 6.18 & 6.42 & 6.61 & 6.40 & 0.05 & $*$ & NS & NS \\
\hline $\mathrm{pH}_{24 \mathrm{~h}}$ & 5.39 & 5.38 & 5.47 & 5.44 & 5.54 & 5.49 & 0.02 & $* *$ & NS & NS \\
\hline Drip $\operatorname{loss}_{24 \mathrm{~h}} \%$ & 1.94 & 1.88 & 2.78 & 2.60 & 1.12 & 1.33 & 0.21 & $*$ & NS & NS \\
\hline Drip $\operatorname{loss}_{48 \mathrm{~h}} \%$ & 4.11 & 2.45 & 5.64 & 5.37 & 2.91 & 3.71 & 0.38 & * & NS & NS \\
\hline Opto-star value & 86.65 & 84.32 & 87.68 & 85.74 & 87.84 & 86.76 & 0.45 & NS & NS & NS \\
\hline IMF \% & 1.44 & 1.02 & 2.26 & 1.02 & 2.35 & 1.72 & 0.17 & NS & $*$ & NS \\
\hline Moisture \% & 76.99 & 76.95 & 75.61 & 77.88 & 73.77 & 73.79 & 0.40 & $* *$ & NS & NS \\
\hline Ash \% & 1.26 & 1.29 & 1.14 & 1.24 & 1.17 & 1.23 & 0.01 & $* *$ & $* *$ & NS \\
\hline
\end{tabular}

NS - Non-significant; $\mathrm{P}>0.05 ; * * \mathrm{P}<0.01$ and $* \mathrm{P}<0.05$.

LEA - Loin eye area; BF - Backfat thickness; IMF - Intramuscular fat.

Numerous researchers have investigated the differences in meat quality traits among different pig breeds: For example, Iberian pigs had a significantly higher backfat depth and intramuscular fat percentage than the Landrace at a slaughter weight of $100 \mathrm{~kg}$ (Serra et al., 1998). Korean native pigs exhibited a higher muscle fat content and backfat thickness than European meat breeds (Kim et al., 2008). As expected, the LEA of the Landrace was higher $(\mathrm{P}<0.01)$ than that of the Lantang, and BF was higher $(\mathrm{P}<0.05)$ in the Lantang. The Lantang also had a higher intramuscular fat content $(\mathrm{P}<0.05)$ and lower ash percentage $(\mathrm{P}<0.01)$. The difference in LEA between Lantang and Landrace indirectly showed that Landrace might have a higher lean percentage and thus better carcass traits.

To measure the development of fibre type composition of the two pig breeds, myosin ATPase and SDH activities were used to differentiate fibre types $\beta \mathrm{R}, \alpha \mathrm{R}$ and $\alpha \mathrm{W}$. The result of staining was similar to a previous study (Solomon \& Dunn, 1988) where the $\beta$ R fibres stained the darkest, $\alpha \mathrm{R}$ fibres stained at a intermediate intensity and the $\alpha \mathrm{W}$ fibres deposited negligible amounts of stain. A clear difference in histological characteristics of muscle fibres was observed between different ages (Table 4). The number percentage of $\alpha \mathrm{R}$ and $\alpha \mathrm{W}$, and muscle fibre cross-sectional area differed $(\mathrm{P}<0.01)$ between different ages. Previous studies suggested that age was a key factor for development of muscle fibres. After the age of eight weeks the percentage of type I (slow-twitch oxidative type) in pigs gradually decreases, and type II (fast-twitch glycolytic type) increases (Suzuki \& Cassens, 1980). In rats, after the age of 21 days, the population of FG fibres with high glycolytic activity increased at the expense of FOG fibres, suggesting FOG fibres are transformed to FG (Punkt et al., 2004). The increase in the number percentage of fast glycolytic fibres and cross-sectional area might lead to lean growth because fast glycolytic fibres had a higher cross-sectional area, while growth rate, carcass leanness and loin eye area were positively related to fibre cross-sectional area (Larzul et al., 1997). 


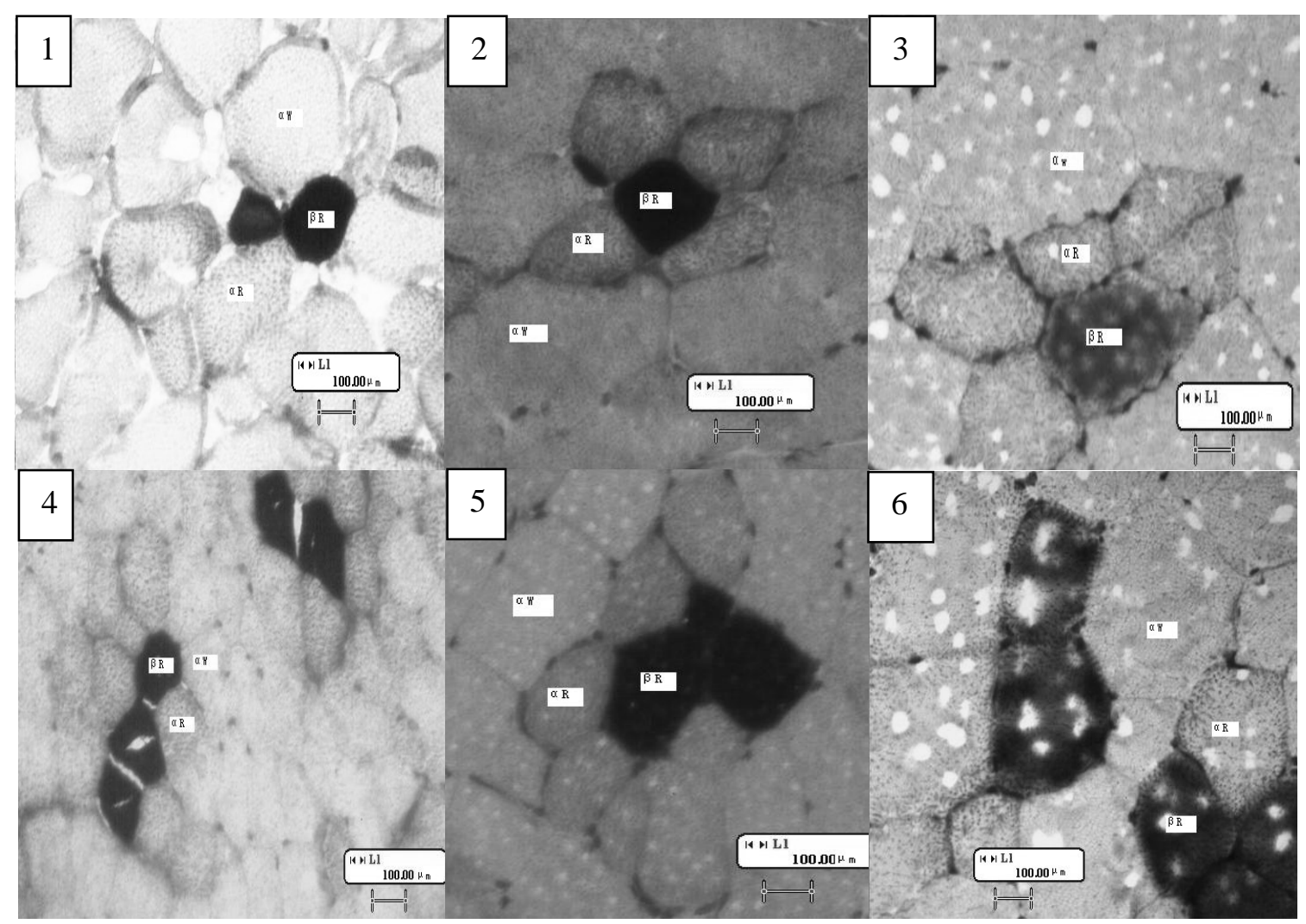

Figure 1/2/3 Histological image of Landrace at the ages of 60, 90 and 150 days.

Figure 4/5/6 Histological image of Lantang at the ages of 60, 90 and 150 days.

Table 4 Muscle fibre characteristics of the longissimus muscle in the Lantang (LT) and Landrace (LR) pigs

\begin{tabular}{|c|c|c|c|c|c|c|c|c|c|c|}
\hline & \multicolumn{2}{|c|}{60 days } & \multicolumn{2}{|c|}{90 days } & \multicolumn{2}{|c|}{150 days } & \multirow[b]{2}{*}{ s.e.m. } & \multicolumn{3}{|c|}{ Significant level } \\
\hline & LT & LR & LT & LR & LT & LR & & Age & Breed & Age $\times$ Breed \\
\hline \multicolumn{11}{|c|}{ Number percentage (\%) } \\
\hline$\beta R$ & 13.06 & 14.71 & 12.47 & 12.59 & 10.58 & 10.54 & 0.68 & NS & NS & NS \\
\hline$\alpha \mathrm{R}$ & 25.48 & 28.37 & 19.92 & 13.91 & 19.74 & 15.13 & 1.11 & $* *$ & NS & $* *$ \\
\hline$\alpha \mathrm{W}$ & 61.45 & 56.93 & 67.62 & 73.50 & 69.67 & 74.34 & 1.52 & $* *$ & NS & NS \\
\hline \multicolumn{11}{|c|}{ Cross-sectional area $\left(\mu \mathrm{m}^{2}\right)$} \\
\hline$\beta R$ & 791 & 717 & 1294 & 1252 & 2527 & 3523 & 267 & $* *$ & NS & NS \\
\hline$\alpha \mathrm{R}$ & 1157 & 1104 & 1618 & 1675 & 2868 & 4469 & 303 & $* *$ & NS & NS \\
\hline$\alpha \mathrm{W}$ & 1833 & 1737 & 2564 & 2414 & 4327 & 6055 & 414 & $* *$ & NS & NS \\
\hline
\end{tabular}

NS - Non-significant, $\mathrm{P}>0.05$ and $* * \mathrm{P}<0.01$.

$\beta \mathrm{R}$ - Slow twitch red; $\alpha \mathrm{R}$ - Fast twitch red; $\alpha \mathrm{W}$ - Fast twitch white.

There are a few studies on the comparison of muscle fibre characteristics between different pig breeds. The longissimus muscle of Hampshire and Finnish Landrace breeds contained a significantly higher percentage of type I fibres and a lower percentage of type IIB fibres than the Yorkshire (Ruusunen \& Puolanne, 1997). The proportion of type I fibres was higher and their diameter was larger in Iberian pigs than in Landrace pigs, while the opposite occurred for the proportion and diameter in type 2B fibres (Serra et al., 1998). In the present study the differences in the number percentage of fibre types and cross-sectional area between the Lantang and Landrace were small (Table 4). Such small difference might be due to the large difference in their slaughter weight. Increasing weight together with age led to an enlargement of $\beta R$ and $\alpha \mathrm{W}$ muscle fibres in 
Table 5 The relative expression of MyHC-slow and MyHC-IIb in longissimus muscle of the Lantang (LT) and Landrace (LR) pigs

\begin{tabular}{|c|c|c|c|c|c|c|c|c|c|c|}
\hline & \multicolumn{2}{|r|}{60 days } & \multicolumn{2}{|c|}{90 days } & \multicolumn{2}{|r|}{150 days } & \multirow[b]{2}{*}{ s.e.m } & \multicolumn{3}{|c|}{ Significant level } \\
\hline & LT & $\overline{\mathrm{LR}}$ & LT & $\overline{L R}$ & LT & $\overline{\mathrm{LR}}$ & & Age & Breed & Age $\times$ Breed \\
\hline MyHC-slow/18S & 2.28 & 2.25 & 5.65 & 4.39 & 7.05 & 6.54 & 0.58 & $* *$ & NS & NS \\
\hline MyHC-IIb/18S & 9.68 & 9.70 & 11.65 & 17.25 & 8.15 & 13.13 & 1.17 & * & $*$ & NS \\
\hline
\end{tabular}

NS - Non-significant, $\mathrm{P}>0.05 ; * * \mathrm{P}<0.01$ and $* \mathrm{P}<0.05$.

crossbred Duroc $\times$ (Large White $\times$ Landrace) barrows without changing the muscle histochemical profile (Candek-Potokar et al., 1999).

Table 5 is an analysis of the relative expression of MyHC-slow and MyHC-IIb mRNA of the longissimus muscle from the two breeds. Strong age effects were observed in the relative expression of MyHC-slow and MyHC-IIb ( $<0.05)$. There are only a few reports on the development of MyHC in pigs on the mRNA level. Abrupt increases in proportion of the ratio of MyHC-Ilb mRNA were found in Erhualian and Large White pigs during postnatal growth from three to 45 days of age (Zhao et al., 2004). The effects of postnatal development on four major sarcomeric MyHCs (i.e., slow, IIa, IIx and IIb) in pig skeletal muscle were very similar at the mRNA and protein levels, suggesting a transcriptional regulation (Lefaucheur et al., 2004). In this study, the increase of the relative expression of MyHC-slow and MyHC-IIb mRNA suggests that the protein of MyHC-slow and MyHC-IIb might also increase to exhibit their muscle growth.

Interestingly, there was a breed effect in the relative expression of MyHC-IIb mRNA $(\mathrm{P}<0.05)$ (Table 5). The Landrace showed a higher $(\mathrm{P}<0.05)$ expression of MyHC-IIb than the Lantang. Similarly, pigs carrying the halothane gene exhibited more MyHC-IIb and less MyHC-slow than pigs without the halothane gene (Depreux et al., 2002). Meishan pigs exhibited a decrease in the relative fibre type specific expression of MyHC-IIb in the longissimus muscle (-25\%) compared with Large White pigs (Lefaucheur et al., 2004). Above data showed that there are differences in expression of MyHC-IIb in the longissimus muscle between different breeds and that the growth rate might be one of the major reasons for this phenomenon. Growth rate influences muscle fibre properties only in light muscles such as longissimus, gluteus superficialis and semimembranosus, and not in dark muscles such as infra spinam and masseter (Ruusunen \& Puolanne, 2004). Muscle fibre characteristics have a profound influence on meat quality and carcass quality. The larger occurrence of the fast glycolytic MyHC-2b fibres in the longissimus muscle of pigs could account for the less favourable quality traits noted (Chang et al., 2003). Similarly, the percentage of type IIb fibre was negatively related to $\mathrm{pH}_{45}$ min, but positively to $\mathrm{R}$-value and drip loss (Ryu \& Kim, 2005). These studies showed that increasing the percentage of type IIb fibre led to the deterioration of meat quality. In this study the difference in relative expression of MyHC-IIb between Lantang and Landrace pigs might be one of the major reasons for differences in their meat quality and carcass traits.

\section{Conclusions}

The Lantang had a significantly higher BF and IMF content in the longissimus muscle than the Landrace, while the LEA and ash content in Landrace muscle were significantly higher than in the Lantang. The changes in the development of LEA coincided with the changes in the development of the muscle fibre cross-section area. The real time RT-PCR experiment indicated that the Landrace had a significantly higher expression level of MyHC-IIb mRNA than the Lantang. The relative expression of MyHC-slow and MyHC-IIb in the longissimus muscle increased significantly between 60 and 150 days of age. The developmental differences in muscle fibre characteristics between the Lantang and Landrace might be one of reasons for the differences between breeds in carcass and meat quality traits.

\section{Acknowledgements}

This work was supported by National Basic Research Programme of China (Project No: 2004CB117501) and joint grants from China Natural Research and Guangdong province (Project No: u0731004). 


\section{References}

Ashmore, C.R. \& Doerr, L., 1971. Comparative aspects of muscle fibre types in different species. Exp. Neurol. $31,408-418$.

Brooke, M.H. \& Kaiser, K.K., 1970. Three "myosin adenosine triphosphatase" systems: The nature of their pH lability and sulfhydryl dependence. J. Histochem. Cytochem. 18, 670-672.

Candek-Potokar, M., Lefaucheur, L., Zlender, B. \& Bonneau, M., 1999. Effect of slaughter weight and/or age on histological characteristics of pig longissimus dorsi muscle as related to meat quality. Meat Sci. 52, 195-203.

Chang, K.C., da Costa, N., Blackley, R., Southwood, O., Evans, G., Plastow, G., Wood, J.D. \& Richardson, R.I., 2003. Relationships of myosin heavy chain fibre types to meat quality traits in traditional and modern pigs. Meat Sci. 64, 93-103.

Depreux, F.F.S., Grant, A.L. \& Gerrard, D.E., 2002. Influence of halothane genotype and body-weight on myosin heavy chain composition in pig muscle as related to meat quality. Livest. Prod. Sci. 73, 265-273.

Eggert, J.M., Depreux, F.F.S., Schinckel, A.P., Grant, A.L. \& Gerrard, D.E., 2002. Myosin heavy chain isoforms account for variation in pork quality. Meat Sci. 61, 117-126.

Essen-Gustavsson, B., Karlstrom, K. \& Lundstrom, K., 1992. Muscle fibre characteristics and metabolic response at slaughter in pigs of different halothane genotypes and their relation to meat quality. Meat Sci. $31,1-11$.

Essen-Gustavsson, B., Karlsson, A., Lundstrom, K. \& Enfalt, A.C., 1994. Intramuscular fat and muscle fibre lipid contents in halothane-gene-free pigs fed high or low protein diets and its relation to meat quality. Meat Sci. 38, 269-277.

Honikel, K.O., Kim, C.J., Hamm, R. \& Roncales, P., 1986. Sarcomere shortening and their influence on drip loss. Meat Sci. 16, 267-282.

Kim, N.K., Lim, J.H., Song, M.J., Kim, O.H., Park, B.Y., Kim, M.J., Hwang, I.H. \& Lee, C.S., 2008. Comparisons of longissimus muscle metabolic enzymes and muscle fibre types in Korean and western pig breeds. Meat Sci. 78, 455-460.

Larzul, C., Lefaucheur, L., Ecolan, P. \& Gogue, J., 1997. Phenotypic and genetic parameters for longissimus muscle fibre characteristics in relation to growth, carcass, and meat quality traits in large white pigs. J. Anim. Sci. 75, 3126-3137.

Lefaucheur, L., Milan, D., Ecolan, P. \& Le Callennec, C., 2004. Myosin heavy chain composition of different skeletal muscles in Large White and Meishan pigs. J. Anim. Sci. 82, 1931-1941.

Park, B.Y., Kim, N.K., Lee, C.S. \& Hwang, I.H., 2007. Effect of fibre type on postmortem proteolysis in longissimus muscle of Landrace and Korean native black pigs. Meat Sci. 77, 482-491.

Peter, J.B., Barnard, R.J., Edgerton, V.R., Gillespie, C.A. \& Stempel K.E., 1972. Metabolic profiles of three fiber types of skeletal muscle in guinea pigs and rabbits. Biochem. 11, 2627-2633.

Punkt, K., Naupert A. \& Asmussen G., 2004. Differentiation of rat skeletal muscle fibres during development and ageing. Acta Histochim. 106, 145-154.

Ruusunen, M. \& Puolanne, E., 1997. Comparison of histochemical properties of different pig breeds. Meat Sci. 45, 119-125.

Ruusunen, M. \& Puolanne, E., 2004. Histochemical properties of fibre types in muscles of wild and domestic pigs and the effect of growth rate on muscle fibre properties. Meat Sci. 67, 533-539.

Ryu, Y.C. \& Kim, B.C., 2005. The relationship between muscle fibre characteristics, postmortem metabolic rate, and meat quality of pig longissimus dorsi muscle. Meat Sci. 71, 351-357.

Serra, X., Gil, F., Perez-Enciso, M., Oliver, M.A., Vazquez, J.M., Gispert, M., Diaz, I., Moreno, F., Latorre, R. \& Noguera, J.L., 1998. A comparison of carcass, meat quality and histochemical characteristics of Iberian (Guadyerbas line) and Landrace pigs. Livest. Prod. Sci. 56, 215-223.

Solomon, M.B. \& Dunn, M.C., 1988. Simultaneous histochemical determination of three fiber types in single sections of ovine, bovine and porcine skeletal muscle. J. Anim. Sci. 66, 255-264.

Suzuki, A. \& Cassens, R.G., 1980. A histochemical study of myofiber types in muscle of the growing pig. J. Anim. Sci. 51, 1449-1461.

Zhao, R.Q., Yang, X.J., Xu, Q.F., Wei, X.H., Xia, D. \& Chen, J., 2004. Expression of GHR and PGC-1 alpha in association with changes of MyHC isoform types in longissimus muscle of Erhualian and Large White pigs (Sus scrofa) during postnatal growth. Anim. Sci. 79, 203-211. 